\title{
Activation energy of time-dependent martensite formation in steel
}

\author{
Villa, Matteo; Somers, Marcel A. J.
}

Published in:

Proceedings of the International Conference on Martensitic Transformations: Chicago

Link to article, DOI:

10.1007/978-3-319-76968-4_2

Publication date:

2018

Document Version

Peer reviewed version

Link back to DTU Orbit

Citation (APA):

Villa, M., \& Somers, M. A. J. (2018). Activation energy of time-dependent martensite formation in steel. In A. Stebner, G. Olson, V. Levitas, E. De Moo, O. Benafan, I. Karaman, M. Asle Zaeem, P. Anderson, D. Rowenhorst, A. Saxena, R. Hamilton, A. Pelton, P. Müllner, M. Mills, \& R. Komai (Eds.), Proceedings of the International Conference on Martensitic Transformations: Chicago (pp. 13-19). Springer. The Minerals, Metals \& Materials Series https://doi.org/10.1007/978-3-319-76968-4_2

\section{General rights}

Copyright and moral rights for the publications made accessible in the public portal are retained by the authors and/or other copyright owners and it is a condition of accessing publications that users recognise and abide by the legal requirements associated with these rights.

- Users may download and print one copy of any publication from the public portal for the purpose of private study or research.

- You may not further distribute the material or use it for any profit-making activity or commercial gain

- You may freely distribute the URL identifying the publication in the public portal 


\title{
Activation energy of time-dependent martensite formation in steel
}

\author{
Matteo Villa*, Marcel A.J. Somers \\ Technical University of Denmark, Department of Mechanical Engineering, DK 2800 Kongens Lyngby, \\ Denmark \\ matv@mek.dtu.dk (+45 45252221), somers@mek.dtu.dk (+45 45252250)
}

\begin{abstract}
The kinetics of $\left\{\begin{array}{lll}5 & 5 & 7\end{array}\right\}_{\gamma}$ lath martensite formation in (wt-\%) $17 \mathrm{Cr}-7 \mathrm{Ni}-1 \mathrm{Al}-0.09 \mathrm{C}$ and $15 \mathrm{Cr}-7 \mathrm{Ni}-2 \mathrm{Mo}-1 \mathrm{Al}-$ $0.08 \mathrm{C}$ steels was assessed with magnetometry at sub-zero Celsius temperatures. Samples were cooled to $77 \mathrm{~K}$ by immersion in boiling nitrogen to suppress martensite formation. Thereafter, thermally activated martensite formation was monitored during: (i) isochronal (re)heating at different heating rates; (ii) isothermal holding at temperatures between 120 and $310 \mathrm{~K}$. The activation energy, $\mathrm{E}_{\mathrm{A}}$, of thermally activated martensite formation was quantified from the results of both isochronal and isothermal tests by applying a Kissinger-like method. In addition, the isothermal data was interpreted applying the approach presented by Borgenstam and Hillert. The results of the independent quantification methods were consistent and indicated an $E_{\mathrm{A}}$ in the range $9013 \mathrm{~kJ} \mathrm{~mol}^{-}$ ${ }^{1}$. Thereafter, the two methods were applied to evaluate the data available in the literature. The overall analysis showed that $E_{A}$ varies in the range $2 \square 27 \mathrm{~kJ} \mathrm{~mol}^{-1}$ and increases logarithmically with the total fraction of
\end{abstract} interstitials in the steel.

Keywords: isothermal martensite; transformation kinetics; martensitic steel

\section{Introduction}

The design of martensitic steels requires models to accurately describe the kinetics of the austenite-tomartensite transformation in this class of materials. In early work, martensitic transformations were considered athermal, meaning that the degree of transformation is determined exclusively by the lowest temperature reached, independent of time [1]. This approach has remained [2] and, in the large majority of cases, allows a consistent description of the transformation kinetics. Nevertheless, martensite formation can also proceed isothermally or, rather, time-dependent, particularly at sub-zero Celsius temperatures.

The first evidence of time-dependent martensite formation was reported in 1948 [3]. Extensive evidence followed (see Refs. [4,5]) and in the 1990s the isothermal behaviour was brought to a rationalization as a common characteristic of martensite formation in ferrous alloys [6]. This implies that martensite formation in steel can be suppressed by sufficiently fast cooling to a temperature where the transformation proceeds (virtually) infinitely slowly. Consistently, it was shown in several cases (see Refs. [4,5,7]) that martensite formation can be partly suppressed by fast cooling to temperatures $\mathrm{T} \leq 77 \mathrm{~K}$, and the transformation can continue on subsequent (re)heating. Also, the transformation can be fully suppressed, as firstly demonstrated in 1953 for Fe-Ni-Mn alloys [8], in 1960 for stainless steel [9] and in 1990 for Fe-Ni alloys [10].

Conversely, the possibility to form martensite at temperatures as low as $4 \mathrm{~K}$ was demonstrated already in 1950 [11] and is evidence that the transformation in the investigated alloys is un-suppressible (i.e., intrinsically athermal). Martensite formation at $4 \mathrm{~K}$ also indicates that the growth of martensite units does not determine the overall rate of the isothermal process. It was established as early as the 1930s-1950s [12-14] that the duration of an austenite-to-martensite transformation event can be of the order of a small fraction of a second and that the growth rate of the martensite units can be independent of temperature within a significantly large temperature interval (i.e., growth is athermal) $[14,15]$. Nevertheless, time-dependent growth of martensite has been observed several times (see Ref. 16).

To reconcile the above experimental observations, it has been suggested that the martensite sub-structure controls the kinetics of martensite formation [13, 17-19]: athermal martensite is internally twinned and timedependent martensite is internally slipped. This straightforward description is, unfortunately, not consistent with all experiments. Slow growth of martensite always involves slipped sub-structures; however, slipped martensite can also grow instantaneously [20,21]. Furthermore, the transformation of austenite into slipped martensite can

\footnotetext{
* corresponding author
} 
be suppressed by fast cooling [22-24]; on the other hand, slipped martensite can form at $4 \mathrm{~K}$ (see, for example, Ref. 11). Evidently, the kinetics of martensitic transformations, the roles of nucleation and growth and the significance of the martensite substructure are incompletely understood.

Following Huizing and Klostermann [25], we recently suggested that the products of martensitic transformations in steel should be classified into two groups [26]:

i. $\quad$ chiebung, $S$, martensite corresponds to internally slipped $\{557\}_{\gamma}$ lath martensite and to the internally slipped product growing on $\left\{\begin{array}{llll}2 & 2 & 5\end{array}\right\}_{\gamma}$ plate and $\left\{\begin{array}{llll}2 & 5 & 9\end{array}\right\}_{\gamma}$ lenticular martensites. $S$ martensite is suppressible and cannot form at an observable rate at temperatures approaching absolute zero. The growth of $\mathrm{S}$ martensite can be time dependent.

ii. Umklapp, $U$, martensite corresponds to twinned $\left\{\begin{array}{llll}3 & 10 & 15\end{array}\right\}_{\gamma}$ thin plate martensite, to the twinned parts of the $\left\{\begin{array}{lll}2 & 25\end{array}\right\}_{\gamma}$ plate and $\left\{\begin{array}{lll}2 & 5 & 9\end{array}\right\}_{\gamma}$ lenticular martensites, as well as to internally slipped strain induced and $\left\{\begin{array}{lll}1 & 1 & 2\end{array}\right\}_{\gamma}$ martensites. $U$ martensite is un-suppressible and can form at $4 \mathrm{~K}$. The growth of $\mathrm{U}$ martensite is instantaneous.

Additionally, we suggested that the existing kinetics models, which typically describe the kinetics of martensite formation in steel as nucleation-controlled (i.e., implicitly assuming instantaneous growth) and define nucleation as un-suppressible upon reaching a certain critical driving force for transformation, $\Delta G_{C}$ (see Ref. 4), apply to $U$ martensite, but cannot describe the kinetics of $\mathrm{S}$ martensite formation. For the latter case, a different approach appears necessary.

An alternative approach to describe the kinetics of isothermal martensite formation was presented by Borgenstam and Hillert [27]. They focused on the evolution of the transformation rate versus temperature and described the transformation rate in terms of chemical reaction rate theory as the product of the normalized chemical driving force, $\Delta G / R T$, and the probability for growth, $\exp \left(-E_{A} / R T\right)$, where $\Delta G$ is the chemical driving force for martensite formation, $\mathrm{R}$ is the gas constant, $\mathrm{T}$ is the temperature and $E_{A}$ is the activation energy for the formation of isothermal martensite. This approach can be considered to describe the kinetics of $\mathrm{S}$ martensite formation because it (i) does not require a priori assumptions on the rate-determining mechanism and (ii) indicates that, provided that cooling is sufficiently fast, martensite formation can be suppressed. However, modelling of the kinetics of transformation requires information on $E_{A}$.

Following Borgenstam and Hillert, $E_{A}$ is determined from the slope of the straight line obtained by plotting isothermal data in terms of $-1 / T$ versus $\ln \left(t\left(M_{s i} / T-1\right)\right)$, where $\mathrm{T}, \mathrm{t}$, and $M_{s i}$ are the temperature of isothermal holding, the time for obtaining a low fraction, say $<0.05$, of martensite, and the maximum temperature at which martensite formation can progress isothermally, respectively. Unfortunately, this quantification method can be applied only in a very limited number of cases, where marked isothermal behaviour is obtained, which makes it particularly suitable only for the case of Fe-Ni-Mn and Fe-Ni-Cr alloys transforming isothermally at sub-zero Celsius temperatures.

In recent work [26], $E_{A}$ was determined by applying a Kissinger-like approach (see Ref. 28). In a Kissingerlike analysis, $E_{A}$ is determined either from the time lapse to a fixed degree of transformation in a series of isothermal tests at various holding temperatures or from the evolution of the temperature at which a certain transformed fraction is reached in a series of isochronal experiments at various heating/cooling rates. Kissingerlike methods are less robust than the approach by Borgenstam and Hillert because they do not take $\Delta G$ into account. Practically, this would imply a systematic underestimation of $E_{A}$. The effect is more pronounced for data acquired close to equilibrium conditions (i.e., at temperatures close to $M_{s i}$ ). An advantage of a Kissingerlike method is that it can be applied for isochronal conditions, thus allowing determination of $E_{A}$ in all systems where martensite formation can be, at least partially, suppressed upon fast cooling to a sufficiently low temperature. Consistently, in Ref. 26, various Fe-based alloys and commercial steel grades, developing $\left\{\begin{array}{l}5 \\ 5\end{array} 7\right\}_{\gamma}$, $\left\{\begin{array}{lll}2 & 2 & 5\end{array}\right\}_{\gamma}$, and $\left\{\begin{array}{lll}2 & 5 & 9\end{array}\right\}_{\gamma}$ martensites, were cooled to $77 \mathrm{~K}$ by immersion in boiling nitrogen. The transformation was then followed during subsequent isochronal (re)heating and $E_{A}$ was determined from the slope of the straight line obtained by plotting $\ln \left(T_{f^{\prime}}{ }^{2} / \phi\right)$ versus $1 / T_{f^{\prime}}$, where $T_{f^{\prime}}$ is the temperature corresponding to a fixed stage of transformation, $f^{\prime}$, and $\phi$ is the heating rate.

In relation to the results of these analyses, Borgenstam and Hillert [27] suggested that small variations of chemical composition do not significantly affect the kinetics of the transformation. Under this assumption, isothermal data collected for Fe-Ni-Mn and Fe-Cr-Ni alloys with comparable total contents of substitutional atoms, but different levels of interstitial purity, were grouped together. For both series of alloys, their analysis yielded an approximate value of $E_{A} \sim 7 \mathrm{~kJ} \mathrm{~mol}^{-1}$. On the other hand, the Kissinger-like method applied to a broad range of alloys [26] indicated that $E_{A}$ increased with the fraction of interstitial atoms and ranges from 8 to $27 \mathrm{~kJ}$ $\mathrm{mol}^{-1}$. Extrapolation of this data set to low interstitial contents showed striking compatibility with the results obtained according to the approach of Borgenstam and Hillert. The present work aims to validate the two analyses and to obtain reliable information on $E_{A}$ for future modelling of the transformation kinetics. The following two steps were taken to arrive at this validation. 
Firstly, a new series of experiments was conducted on (wt-\%) 17Cr-7Ni-1Al-0.09C (17-7 PH) and 15Cr-7Ni2Mo-1Al-0.08C (15-7 PH) stainless steels, wherein $\{557\}_{\gamma}$ lath martensite (i.e., interpreted as pure $\mathrm{S}$ martensite) develops at sub-zero Celsius temperatures. The experiments included both isothermal and isochronal tests, and the two sets of data were used to assess $E_{A}$ according to the approach presented by Borgenstam and Hillert and the Kissinger-like methods for isothermal and isochronal analysis (cf. Ref. 28), respectively. This part of the work aimed at exploring the importance of the systematic underestimation of $E_{A}$ by Kissinger-like methods.

Secondly, isothermal data considered in Ref. 27 were re-evaluated. As suggested in Ref. 26, $E_{A}$ varies with the logarithm of the interstitial content. Consequently, small variations in low purity level can significantly affect the kinetics of the transformation. To verify this, each data set in Ref. 27 was re-evaluated independently. Additionally, it is noted that the analysis in Ref. 27 did not distinguish between $\{557\}_{\gamma},\{225\}_{\gamma}$, and $\{112\}_{\gamma}$ martensites, which cannot be reconciled with our interpretation of S martensite. Data referring to $\left\{\begin{array}{lll}1 & 1 & 2\end{array}\right\}_{\gamma}$ martensite were excluded in the present analysis.

\section{Materials and methods}

The materials chosen for investigation were steels of types 17-7 PH (17Cr-7Ni-1.Al-0.08C) and 15-7 PH (15Cr-7Ni-2Mo-1 Al-009C). In these alloys, the kinetics of the transformation can be adjusted at convenience by varying the austenitization conditions, and martensite formation on cooling can be fully suppressed [9]. Samples were $\varnothing 3 \mathrm{~mm}$ disks with a thickness of $0.15 \mu \mathrm{m}(17-7 \mathrm{PH})$ and $0.25 \mu \mathrm{m}(15-7 \mathrm{PH})$ thick, supplied by Goodfellow Inc. in as-rolled (17-7 PH) and annealed (15-7 PH) condition, respectively. Samples were electroplated with a layer of pure $\mathrm{Ni}$ (approx. $0.5 \mu \mathrm{m}$ thick) prior to austenitization in order to prevent preferential formation of martensite at the free surface. Austenitization was performed in a continuous Ar flow and consisted in heating at an average rate of $1 \mathrm{~K} \mathrm{~s}^{-1}$ to the austenitization temperature, followed by $180 \mathrm{~s}$ austenitization at temperature and cooling to room temperature at an average rate of $0.7 \mathrm{~K} \mathrm{~s}^{-1}$. The austenitization temperatures chosen were $1253 \mathrm{~K}\left(980^{\circ} \mathrm{C}\right)$ for $\mathrm{PH} 15-7$ and $1283 \mathrm{~K}\left(1010^{\circ} \mathrm{C}\right)$ for $\mathrm{PH} 17-7$. In both cases, the microstructure of the material upon cooling to room temperature consisted of austenite and a minor (3-5\%) presence of delta ferrite situated at the austenite grain boundaries.

The formation of martensite was followed applying magnetometry. Details on the experimental setup as well as on the quantification procedure were given elsewhere [26,29,30]. Two types of tests were performed: isothermal and isochronal. In order to attain identical starting conditions for the isochronal and isothermal data sets, the samples were first cooled to $77 \mathrm{~K}$ in the vibrating sample magnetometer before investigation.

\section{Results and Discussion}

\subsection{From isothermal and isochronal transformation curves to sub-zero Celsius transformation diagrams}

Examples of the experimentally obtained transformation curves for 17-7 PH are presented in Fig. 1. Isothermal data in Fig. 1a indicates that martensite formation is time dependent in the investigated temperature interval, $120-270 \mathrm{~K}$. The highest transformation rate was observed at $195 \mathrm{~K}$. The lowest fraction of martensite forms at $270 \mathrm{~K}$, where less than $0.2 \%$ martensite is obtained after $76 \mathrm{ks}$ isothermal holding. Isochronal data in Fig. 1b shows that martensite forms during continuous heating starting from $77 \mathrm{~K}$. For the highest heating rate of 0.833 $\mathrm{K} \mathrm{s}^{-1}$ (i.e., $50 \mathrm{~K} \mathrm{~min}^{-1}$ ), the transformation barely starts and the process stops at approx. $272 \mathrm{~K}$ with only $1.5 \%$ martensite formed. This temperature is interpreted as $M_{s i}$. For the slowest applied heating rate of $0.00167 \mathrm{~K} \mathrm{~s}^{-1}$ (i.e., $0.1 \mathrm{~K} \mathrm{~min}^{-1}$ ), the transformation starts at approx. $110 \mathrm{~K}$ and saturates at $M_{s i}$ at a maximum value of $74.5 \%$ fraction of martensite, $f$. In the case of PH 15-7 (not shown), the investigated temperature interval was 130$310 \mathrm{~K}$, the highest transformation rate was observed at $230 \mathrm{~K}$ and $M_{s i}$ equalled $315 \mathrm{~K}$. [INSERT FIG. 1]

All data from Fig. 1 for PH 17-7 and the data for PH 15-7 are presented in Fig. 2a and 2b, respectively. The isothermal data are represented by the data arranged along horizontal lines, while the isochronal data are arranged along the curves with increasing slope. Interconnecting points of equal transformed fraction provide Time-Temperature-Transformation (TTT) and Continuous-Heating-Transformation (CHT) diagrams. Analogous to Continuous-Cooling-Transformation, (CCT) diagrams, where the transformation lines are shifted to a lower temperature as compared to the corresponding TTT diagrams, the transformation lines for a CHT diagram are shifted to higher temperature as compared to the lines for the corresponding TTT diagrams. In the following, the experimental data were used to quantify $E_{A}$. [INSERT FIG. 2]

\subsection{Assessment of activation energy for martensite formation}

Following the analysis introduced by Borgenstam and Hillert [27], isothermal data in Fig. 2 are presented as $-1 / T$ versus $\ln \left(t\left(M_{s i} / T-1\right)\right)$ in Fig. 3. At a transformed fraction of $0.4 \%$, there is good correspondence 
between data for PH 17-7 (open symbol) and PH 15-5 (closed symbols). For the higher transformed fractions, the slope of the low temperature asymptote, which is used to quantify $E_{A}$, is of comparable magnitude for the two steels and remains virtually unchanged during transformation. This indicates that the rate-determining step for time-dependent martensite formation in the two materials is comparable and remains largely unaltered during the transformation. Differences in absolute kinetics are ascribed to the effect of the microstructure on the evolution of the phase fraction versus time. The activation energy, $E_{A}$, was evaluated from the slopes of the low temperature asymptotes. To secure a sufficiently robust analysis, only data acquired at temperatures equal or lower than the maximum transformation rate were considered. The analysis was performed for every increase in $f$ by 0.001 and yielded $E_{A}$ within the ranges $9.8 \square 14 \mathrm{~kJ} \mathrm{~mol}^{-1}$ and $8.6 \square 15.3 \mathrm{~kJ} \mathrm{~mol}^{-1}$ (mean values $11.3 \mathrm{~kJ} \mathrm{~mol}^{-1}$ and $12.9 \mathrm{~kJ} \mathrm{~mol}^{-1}$ ) for PH 17-7 and PH 15-7, respectively. [INSERT FIG. 3]

The same data sets were used to estimate $E_{A}$ according to Kissinger-like isothermal method [28], where $E_{A}$ is evaluated from the slope of the straight line obtained by $1 / T$ versus $\ln (t)$. Additionally, isochronal analysis was performed as previously reported [26] using the second data set. Isothermal analysis yielded $7.4 \square 12 \mathrm{~kJ} \mathrm{~mol}^{-1}$ and $7.7 \square 13 \mathrm{~kJ} \mathrm{~mol}^{-1}$ (mean values $9.1 \mathrm{~kJ} \mathrm{~mol}^{-1}$ and $10 \mathrm{~kJ} \mathrm{~mol}^{-1}$ ) for PH 17-7 and PH 15-7, respectively; isochronal analysis yielded $E_{A}$ within the ranges $7.1011 .9 \mathrm{~kJ} \mathrm{~mol}^{-1}$ and $9.9012 .7 \mathrm{~kJ} \mathrm{~mol}^{-1}$ (mean values $9.8 \mathrm{~kJ}$ $\mathrm{mol}^{-1}$ and $11.5 \mathrm{~kJ} \mathrm{~mol}^{-1}$ ) for PH 17-7 and PH 15-7, respectively. Evidently, isothermal and isochronal analyses yield consistent results. Moreover, there is a fair agreement between the results of the Kissinger-like methods and the Borgenstam-Hillert method. As anticipated, the self-consistent (and driving force omitting) Kissingerlike methods yield systematically lower values, albeit negligible within experimental accuracy. The trend is that the Kissinger analysis of the isochronal data set yields activation energy values in between those obtained with the Borgenstam-Hillert analysis and the Kissinger-like analysis of the isothermal data set.

In the following, isothermal data from the literature for Fe-Ni-Mn and Fe-Cr-Ni and previously used in Ref. 27 are revisited to determine $E_{A}$ according to the Borgenstam-Hillert method and the Kissinger-like method. The analysis considered only those alloys developing $\left\{\begin{array}{llll}5 & 5 & 7\end{array}\right\}_{\gamma}$ and $\left\{\begin{array}{lll}2 & 2 & 5\end{array}\right\}_{\gamma}$ martensites and was performed for individual compositions to verify the dependence on interstitial content. Only data sets consisting of at least 3 data points at and below the maximum transformation temperature were taken into account, provided that a linear regression coefficient better than 0.8 was obtained. The results are presented in Fig. 4 along with the values obtained for PH 17-7 and PH 15-7 as described above and compared with the data in Ref. 26. [INSERT FIG. 4]

Again, a systematic underestimation of $\mathrm{E}_{\mathrm{A}}$ for the Kissinger-like method is found as compared to the Borgenstam-Hillert analysis. Clearly, the data is consistent with those for the PH steels investigated in this work. A trend is observed that the activation energy increases with interstitial content for the data in Refs. 3135 , which remained unobserved in the evaluation in Ref. 27. In comparison with an assessment of the dependence of the activation energy on interstitial content obtained for a broad range of iron-based alloys and steels in Ref. 26 (and earlier in Ref. 7), excellent correspondence is obtained and the trend of decreasing activation energy with logarithmic lowering of the interstitial content is confirmed (cf. Fig. 4). A rough quantitative relationship can be obtained by linear fit of data. Recognizing that the data in Ref. 26 rely on a Kissinger-like analysis of isochronal data, the linear fit in Fig. 4 was restricted to this type of analysis, yielding: $\mathrm{E}_{\mathrm{A}}=(27.0 \pm 1.9)+(7.0 \pm 0.8) \cdot \log (C+N) \quad$ Eq. 1 where $\mathrm{C}+\mathrm{N}$ represents the total content of $\mathrm{C}$ and $\mathrm{N}$ atoms in at. fraction. In line with the above-mentioned omission of the driving force in Kissinger-like analyses, this equation is likely to represent an underestimation.

The strong dependence of the activation energy on the interstitial content would be consistent with solidsolution strengthening of austenite and with the idea by Ghosh and Olson [36] that the interaction of solute atoms with the thermally assisted motion of the martensitic interface rate control the isothermal process. At present it is not clear whether $\mathrm{E}_{\mathrm{A}}$ would eventually reach zero for a sufficiently low interstitial content, or whether the formation of S martensite is intrinsically time-dependent. In perspective, to fully understand the nature of martensitic transformation in steel, work should be initiated to address this fundamental question.

\section{Conclusions}

The time-dependent formation of martensite in (wt-\%) 17Cr-7Ni-1 Al-0.09C and 15Cr-7Ni-2Mo-1Al-0.08C steels can be fully suppressed by immersion in boiling nitrogen. The transformation kinetics were studied in isothermal tests and isochronal heating experiments and yielded TTT and CHT (continuous heating transformation) diagrams for martensite formation in the sub-zero Celsius temperature regime.

The activation energy of time-dependent martensite formation was determined by applying the BorgenstamHillert and Kissinger-like methods for isothermal and isochronal analysis. The two approaches yield consistent results and indicated that the activation energy in these steels is $9-13 \mathrm{~kJ} \mathrm{~mol}^{-1}$.

The present data were combined with a large number of partly re-interpreted literature data and establishes a logarithmic dependence on the total fraction of interstitials in the Fe-based alloys/steels, suggesting that solution strengthening determines the rate of isothermal martensite formation at sub-zero Celsius temperature. 


\section{Acknowledgements}

This work was financially supported by the Danish Council for Independent Research [grant number: DFF4005-00223]. The first author acknowledges Otto Møsted fund for financially supporting the participation to ICOMAT 2017.

\section{References}

[1] D.P. Koistinen, R.E. Marburger (1959) A general equation prescribing the extent of the austenite-martensite transformation. Acta Metall., 7(1):59-60.

[2] H.Y. Fei, P. Hedstrom, L. Hoglund, A. Borgenstam (2016) A Thermodynamic-Based Model to Predict the Fraction of Martensite in Steels. Metall. Mater. Trans. 47A(9):4404-4410.

[3] G.V. Kurdyumov, O.P. Maksimova (1948) O kinetike prevrashcheniya austenitica v martensit pri nizikh temperaturah. Dokl Akad Nauk SSSR 61(1):83-86.

[4] N.N. Thadhani, M.A. Meyers (1986) Kinetics of isothermal martensitic transformation. Prog. Mater. Sci. 30:1-37.

[5] V.A. Lobodyuk, E.I. Estrin (2005) Isothermal martensitic transformations. Physics-uspekhi, 48(7):713732.

[6] J.C. Zhao, M.R. Notis (1995) Continuous cooling transformation kinetics versus isothermal transformation kinetics of steels: a phenomenological rationalization of experimental observations. Mater. Sci. Eng. R, 15(4-5):135-207.

[7] M. Villa, T. Christiansen, M.F. Hansen, M. AJ Somers (2015) Investigation of martensite formation in Fe based alloys during heating from boiling nitrogen temperature. Metall. Ita., 11-12:39-46.

[8] R.E. Cech, J.H. Hollomon (1953) Rate of Formation of Isothermal Martensite in Fe-Ni-Mn Alloy. Trans. AIME - J. of Metals 197(5):685-689.

[9] A.P. Gulyaev, V. M. Makarov (1960) Martensitic Transformation, Mechanical Properties, and Structure of Austenitic-Martensitic Stainless Steels. Metal Sci. Heat Treat. 2(8):419-423.

[10] K. Ullakko, M. Nieminen, J. Pietikäinen (1990) Prevention of Martensitic Transformation During Rapid Cooling. Mater. Sci. Forum 56-58:225-228.

[11] S. Kulin, M. Cohen (1950) On the martensitic transformation at temperatures approaching absolute zero. Trans. AIME, 188(9):1139-1143.

[12] H.J. Wiester (1932) Die MartensitKristallisation in Filmbild. Ztsch. Metallkunde 24(11):276-277.

[13] F. Foerster, E. Scheil (1940) Unterschung des zeitlichen Ablaufes von Umklappvorgängen in Metallen. Ztsch. Metallkunde 32(6):165-173.

[14] R.F. Bunshah, R.F. Mehl (1953) Rate of Propagation of Martensite. Trans. AIME, 197(9):1251-1258.

[15] Z.Z. Yu, P. C. Clapp (1989) Growth Dynamics Study of the Martensitic Transformation in Fe-30 Pct Ni Alloys. I. Quantitative Measurements of Growth Velocity. Metall. Trans. 20A(9):1601-1615.

[16] Z. Nishiyama (1978) Martensitic Transformations. Academic Press, New York, p 236-238.

[17] T. Honma, (1958) Studies on Lattice Transformation of Iron Alloy and Cobalt Alloy (No.1). DENKISEIKO 29(4):261-276.

[18] V.V. Nemirovskiy (1968) A Study of the Martensitic Transformation in Iron-Nickel near Compositions Corresponding to a Change in the Mechanisms of the Transformation. Fizika Metallov I Metallovedenie 25(5):900-909.

[19] I. Ya Georgiyeva, O. P. Maksimova (1971) Relation between kinetics and structure during martensitic transformations. Phys. Met. Metallogr. 32(2): 135-146.

[20] K. Takashima, Y. Higo, S. Nunomura (1980) Identification of acoustic emission during the martensite transformation of 304 stainless steel. Scripta Metall. 14(5): 489-491.

[21] K. Takashima, Y. Higo, S. Nunomura (1984) The propagation velocity of the martensitic transformation in 304 stainless steel. Philos. Mag. A 49(2): 231-241.

[22] E.A. Wilson (1994) The $\gamma \rightarrow \alpha$ Transformation in Low Carbon Irons. ISIJ Int. 34(8): 615-630.

[23] D. A. Mirzayev, M.M. Shteynberg, T. N. Ponomareva, V.M. Schastlivtsev (1979) Influence of cooling rate on the position of martensitic transformation points. 1. Carbon steels. Phys. Met. Metallogr.. 47(1): 102111.

[24] D. A. Mirzayev, M.M. Shteynberg, T. N. Ponomareva, V.M. Schastlivtsev (1979) Influence of cooling rate on the position of martensitic transformation points. 2. Alloyed steels. Phys. Met. Metallogr. 47(5): 73-79.

[25] R. Huizing, J.A. Klostermann (1966) The Martensite Transformation in Small (0.1-0.3 Mm) Iron-Nickel Single Crystals. Acta Metall. 14(12): 1693-1702.

[26] M. Villa, M.A.J. Somers (2017) Thermally activated martensite formation in ferrous alloys. submitted for publication.

[27] A. Borgenstam, M. Hillert (1997) Activation Energy for Isothermal Martensite in Ferrous Alloys. Acta 
Mater. 45(2): 651-662.

[28] E.J. Mittemeijer (1992) Analysis of the kinetics of phase transformation. J. Mater Sci, 27(15): 3977-3987.

[29] M. Villa, M.F. Hansen, K. Pantleon, M.A.J. Somers (2015) Anomalous kinetics of lath martensite formation in stainless steel. Mater. Sci. Technol., 31(11): 1355-1361.

[30] Villa, M., M.F. Hansen, M.A.J. Somers (2015) The Sub-Zero Celsius Treatment of Precipitation Hardenable Semi-Austenitic Stainless Steel. Proceedings of the 28th ASM HTS Conf., Detroit, MI, 431435.

[31] C.H. Shih, B. L. Averbach, M. Cohen (1955) Some Characteristics of the Isothermal Martensitic Transformation. J. of Metals 7(1): 183-187.

[32] G. Ghosh, V. Raghavan (1986) The Kinetics of Isothermal Martensitic Transformation in an Fe23.2wt.\%Ni-2.8wt.\%Mn Alloy. Mater. Sci. Eng. 800(1): 65-7

[33] R.E. Cech, J.H. Hollomon (1953) Rate of Formation of Isothermal Martensite in Fe-Ni-Mn Alloy. Trans. AIME - J. of Metals 197(5): 685-689.

[34] M. Holmquist, J.O.Nilsson, A.H. Stigenberg (1995) Isothermal formation of martensite in a 12Cr-9Ni-4Mo maraging stainless steel. Scr. Metal. Mater. 33(9): 1367-1373

[35] Y. Imai, M. Izumiyama, K. Sasaki (1966) Isothermal Martensitic Transformation in Fe-Ni-Cr Alloy. Sci. Report Research Inst., Tohoku Uni. A 18(1): 39-48.

[36] G. Ghosh, G.B. Olson (1994) Kinetics of fcc $\rightarrow$ bcc heterogeneous martensitic nucleation-II. Thermalactivation. Acta Metall. Mater. 42(10): 3371-3379. 
Figure 1. Fraction of martensite $\Delta f$ formed in 17-7 PH during a) isothermal holding at various temperatures and $b$ ) isochronal heating from $80 \mathrm{~K}$ at various heating rates. The legend refers to a) the temperature of isothermal holding in $K$ and $b$ ) the rate of isochronal heating in $K \mathrm{~min}-1$.

Figure 2. Superposition of TTT (full colour) and CHT (faint colour) transformation diagrams for: a) 17-7 PH stainless steel austenitized at $1283 \mathrm{~K}\left(1010^{\circ} \mathrm{C}\right)$ and b) $15-7 \mathrm{PH}$ stainless steel austenitized at $1253 \mathrm{~K}\left(980^{\circ} \mathrm{C}\right)$.

Figure 3. Isothermal data presented in Fig. 2 according to the analysis proposed by Borgenstam and Hillert [26]. Open symbols connected by dashed lines and full symbols connected by dotted lines refer to PH 15-7 and $\mathrm{PH}$ 15-7 steels, respectively. In this present form, data are used to quantify $E_{A}$ from the slope of the low temperature asymptote (schematically presented for $0.4 \%$ fraction transformed).

Figure 4. Activation energy, $E_{A}$, for time-dependent martensite formation as a function of the total atomic fraction of interstitials in the alloy/steel, $C+N$. Full symbols refer to data obtained based on the method presented by Borgenstam and Hillert. Isothermal data: Refs. [32,33] extracted at $1 \%$ and $5 \% \Delta f$ from the reported Figs.; Ref. 31, extracted at 1\% and 5\% from Fig. 1 present tabulated at 0.2\%; Ref. 34, extracted at $20 \% f$ from Fig. 2; Ref. 35, data at 1\% f extracted from the presented figure. Isochronal data were reported in previous work by the present authors [26]. The data is presented such that the error bars in $E_{A}$ are given as the minimum, maximum and average values taking into account the standard error of the estimate for linear regression. Dashed line represent linear fit of data obtained by Kissinger-like methods. 
Fig. 1
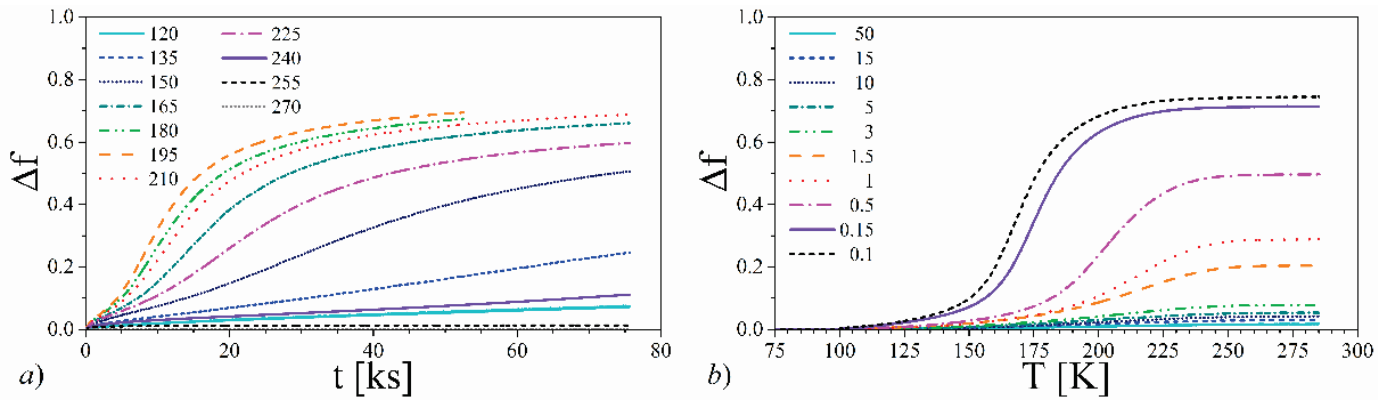

Fig. 2
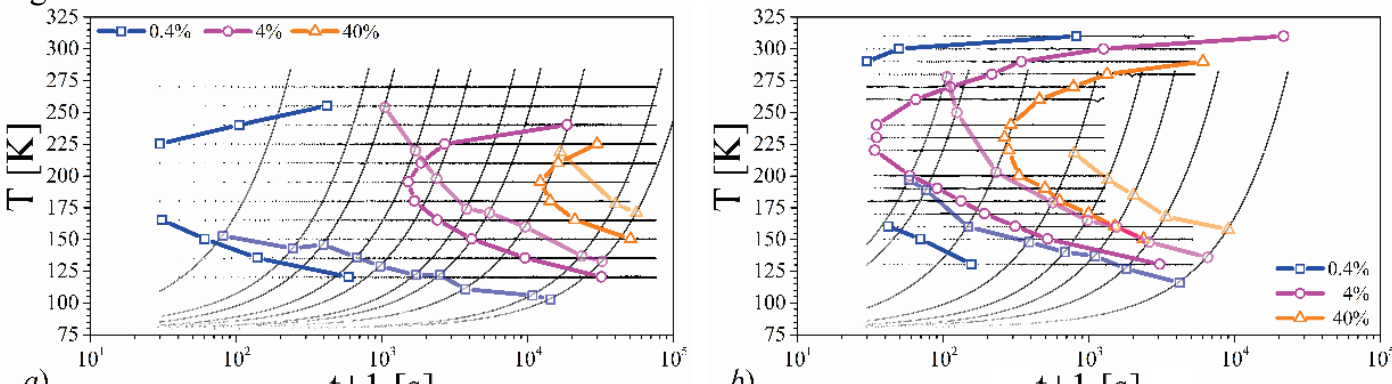

a)

$\mathrm{t}+1[\mathrm{~s}]$

b)

$\mathrm{t}+1[\mathrm{~s}]$

Fig. 3

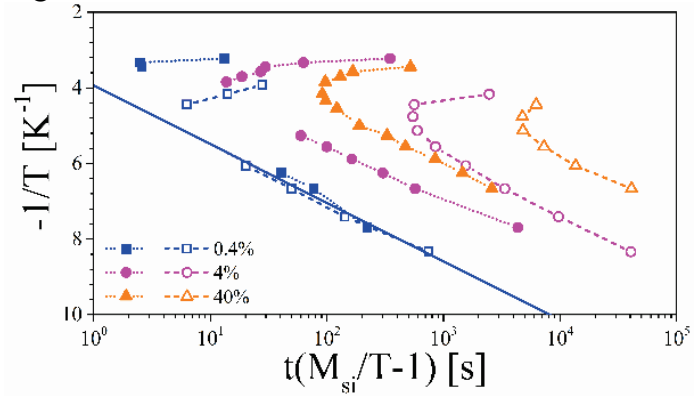

Fig. 4

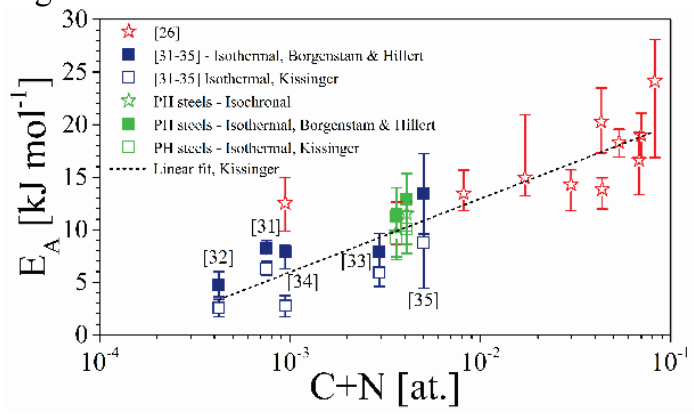

